\title{
Harbour porpoise movement strategy affects cumulative number of animals acoustically exposed to underwater explosions
}

\author{
Geert Aarts $^{1,2, *}$, Alexander M. von Benda-Beckmann ${ }^{3}$, Klaus Lucke ${ }^{1,4}$, \\ H. Özkan Sertlek ${ }^{5}$, Rob van Bemmelen ${ }^{1}$, Steve C. V. Geelhoed ${ }^{1}$, Sophie Brasseur ${ }^{1}$, \\ Meike Scheidat ${ }^{1}$, Frans-Peter A. Lam ${ }^{3}$, Hans Slabbekoorn ${ }^{5}$, Roger Kirkwood ${ }^{1}$ \\ ${ }^{1}$ Wageningen University \& Research, Wageningen Marine Research, Ankerpark 27, 1781 AG Den Helder, The Netherlands \\ ${ }^{2}$ Wageningen University \& Research, Department of Aquatic Ecology \& Water Quality Management (AEW), \\ Droevendaalsesteeg 3a, Building 100, 6708 PB Wageningen, The Netherlands \\ ${ }^{3}$ TNO Acoustics and Sonar, Oude Waalsdorperweg 63, 2597 AK, The Hague, The Netherlands \\ ${ }^{4}$ Centre for Marine Science \& Technology, Curtin University, GPO Box U1987, Perth, WA 6845, Australia \\ ${ }^{5}$ Leiden University, Institute of Biology Leiden, Sylviusweg 72, 2333 BE Leiden, The Netherlands
}

\begin{abstract}
Anthropogenic sound in the marine environment can have negative consequences for marine fauna. Since most sound sources are intermittent or continuous, estimating how many individuals are exposed over time remains challenging, as this depends on the animals' mobility. Here we explored how animal movement influences how many, and how often, animals are impacted by sound. In a dedicated study, we estimated how different movement strategies affect the number of individual harbour porpoises Phocoena phocoena receiving temporary or permanent hearing loss due to underwater detonations of recovered explosives (mostly WWII aerial bombs). Geo-statistical distribution models were fitted to data from 4 marine mammal aerial surveys and used to simulate the distribution and movement of porpoises. Based on derived doseresponse thresholds for temporary (TTS) or permanent threshold shifts (PTS), we estimated the number of animals affected in a single year. When individuals were free-roaming, an estimated 1200 and 24000 unique individuals would suffer PTS and TTS, respectively. This equates to respectively 0.50 and $10 \%$ of the estimated North Sea population. In contrast, when porpoises remained in a local area, fewer animals would receive PTS and TTS (1100 [0.47\%] and 15000 [6.5\%], respectively), but more individuals would be subjected to repeated exposures. Because most anthropogenic sound-producing activities operate continuously or intermittently, snapshot distribution estimates alone tend to underestimate the number of individuals exposed, particularly for mobile species. Hence, an understanding of animal movement is needed to estimate the impact of underwater sound or other human disturbance.
\end{abstract}

KEY WORDS: Marine mammals · Anthropogenic sound · Individual-based model $\cdot$ Cumulative effects · Impact assessment - Population consequences of disturbance - Species distribution . Acoustics

\section{INTRODUCTION}

Human activities in the marine environment such as offshore pile-driving, seismic surveys and detonation of explosives produce sound impulses of high

\footnotetext{
*Corresponding author: geert.aarts@wur.nl
}

amplitude (Ainslie et al. 2009). Extreme levels of these anthropogenic sounds have the potential to disturb or injure marine mammals (Richardson et al. 1995, Nowacek et al. 2007, Southall et al. 2007). Potential population-level consequences of sound

() The authors 2016. Open Access under Creative Commons by Attribution Licence. Use, distribution and reproduction are unrestricted. Authors and original publication must be credited. 
are of particular concern (NRC 2005), which has led to the development and application of a general framework for estimating population consequences of disturbance (PCoD; NRC 2005, New et al. 2014, King et al. 2015, Harwood et al. 2016). The PCoD model describes how changes in an individual's behaviour and physiology may affect its health and vital rates, and how this may ultimately influence population dynamics. To assess whether specific human activities have long-term population-level impacts, it is necessary to know the number of individuals and proportion of the population exposed to a level of sound that is associated with negative consequences (Thompson et al. 2013b, Nabe-Nielsen et al. 2014, King et al. 2015). However, estimating the total number of individuals exposed to specific sound sources is challenging. Often only a fraction of the population is observed, and most marine mammals move large distances, changing their exposure probability, and consequently affecting the cumulative number of individuals exposed.

For single sound exposures, estimating the number of individuals affected can be achieved using the following steps. First, maps of sound exposure levels (SELs) or sound pressure levels (SPLs) are developed using frequency-specific sound source levels and sound propagation models. Next, experimentally derived dose-response relationships define the received level at which hearing impairment or behavioural responses are expected to occur (e.g. Southall et al. 2007, Lucke et al. 2009, Kastelein et al. 2012, Tougaard et al. 2015). The estimated SEL or SPL maps can then be overlaid with marine mammal distribution estimates, to estimate the number of individuals exposed to sound levels above the behavioural or auditory effect thresholds.

Although this approach can be used for single sound exposures, with the timescale of the exposure being small compared to the distance travelled by those individuals, it is deficient for the majority of situations, where continuous or intermittent sounds are produced over longer periods. With ongoing and intermittent sounds, individuals that are unaware of the event may (re-)enter the region of high SELs inbetween the sound emission events. Consequently, a larger number of individuals could be exposed than would be expected based on 'snapshot' density estimates. Moreover, individuals that have not vacated the area may receive multiple exposures during a sound production period.

Each type of anthropogenic sound source has unique acoustic characteristics in terms of intensity, spectrum and repetition rate, and may change in location and over time. Underwater explosions (e.g. controlled underwater detonations of recovered bombs, mines and torpedoes from WWII) are unique as they represent single sound events, with the peak sound pressures of the blast wave being one of the highest anthropogenic sound levels produced in the marine environment (Ainslie et al. 2009, Koschinski 2011). Such detonations are conducted on the Dutch Continental Shelf (DCS) by the Royal Netherlands Navy in a controlled manner, to reduce the risk of uncontrolled explosions, which could be dangerous to human life and infra-structure (Koschinski 2011, von Benda-Beckmann et al. 2015). Each year, approximately 100 detonations occur on the DCS. To marine mammals, the sound produced by these explosions could cause acute stress (Reeder \& Kramer 2005), trigger behavioural reactions (Nowacek et al. 2007, Southall et al. 2007), and may lead to temporary or permanent hearing impairment or other physical injury (Ketten 2004, Lucke et al. 2009, Kastelein et al. 2012). Since the detonations occur irregularly in time and space (von Benda-Beckmann et al. 2015), animals are likely to be unable to anticipate and avoid them.

In the North Sea, the harbour porpoise Phocoena phocoena is the most abundant marine mammal, with approximately 230000 individuals estimated from the last survey in 2005 (Hammond et al. 2013). In the southern North Sea, harbour porpoises were virtually absent for several decades but grew exponentially after 1990, presumably as a result of a large-scale range-shift southwards (Camphuysen 2011, Hammond et al. 2013). Coastal sightings and aerial survey data suggest that most harbour porpoises reside in the southern North Sea in winter, and many migrate northwards along the Dutch and German coast in March and April (Scheidat et al. 2012). Although harbour porpoises may remain at a single site for several weeks (e.g. Camphuysen \& Krop 2011), they often cover large distances (>100 km) in a few days (Read \& Westgate 1997, Johnston et al. 2005, Sveegaard et al. 2011, Nabe-Nielsen et al. 2013). Due to their small size and a high metabolism, and living in a cold environment, harbour porpoises require a higher daily food intake as a proportion of their body weight than most other toothed whales (Kastelein 1998). Like other toothed whales, harbour porpoise rely on (high-frequency) echolocation to detect prey. Hence, any impairment of their foraging efficiency, such as displacement to suboptimal habitat in response to anthropogenic sound, or impaired echolocation ability, presumably could reduce the animals' fitness. 
Von Benda-Beckmann et al. (2015) investigated potential impacts of explosive clearance activities conducted by the Royal Netherlands Navy on harbour porpoises on the DCS. That study focused on a temporary or permanent shift of the auditory threshold, known as TTS (temporary threshold shifts) and PTS (permanent threshold shifts), respectively, and estimated that these underwater explosions likely resulted in hundreds to thousands of PTS events annually. However, the total number of individuals exposed could not be estimated. Here, we first conducted a pilot simulation to investigate how movement choices of individuals can influence numbers exposed to a potentially detrimental sound source. We then extended the study of von Benda-Beckmann et al. (2015) by applying individual-based models to investigate the effects of the extremes of movement strategies that harbour porpoises could exhibit (i.e. random dispersal and site fidelity), and thereby deriving improved estimates on the number of individuals receiving PTS or temporary threshold shifts (TTS). This includes a simulation of different movement choices by harbour porpoises in response to explosion events. We base our analyses on $1 \mathrm{yr}$ of distribution data of harbour porpoises in the North Sea, and the timeline and amplitude levels of detonations in the same period. The first general question we aimed to answer is 'How does the interaction between the spacing and timing of explosions, and movement behaviour of the harbour porpoises, influence the exposure probability?' Secondly, we attempted to estimate the total number of porpoises exposed to detonations of underwater explosions on the DCS within a single year, for 2 scenarios (random dispersal and site fidelity). Although the study focusses on harbour porpoises exposed to underwater explosions in the North Sea, the principal idea to use movement simulations (or actual movement data) to study the number of individuals exposed to anthropogenic sound can be of use for many other situations and marine mammal species, and potentially other mobile marine fauna.

\section{METHODS}

\section{Pilot simulation: effect of movement of the animal and sound source on sound exposure}

Both animals and sound sources tend to move through space, influencing how many individuals and how often individual animals are exposed to sound. The location of a sound source can range between coming from a fixed location to moving ran- domly at high speed. For illustrative purposes, here we adopted a simplified simulation to illustrate the extremes with respect to movement of a fictional animal and a sound source, and how it affects the number of animals exposed, and exposure repeatability. A sound source was assumed to be either at a single location or at different locations, selected randomly. It was active at 1 instance each day over a duration of 100 d. Animal movement was simulated on a $100 \times$ $100 \mathrm{~km}$ grid, and those present within $10 \mathrm{~km}$ from the source (an arbitrary distance) were assumed to be negatively impacted (e.g. auditory injury). Note that in the dedicated porpoise study and simulation described below, not this arbitrary distance, but estimated SELs were used to estimate which individuals were impacted. The initial distribution of animals was randomly uniform, after which individuals moved according to different rules. One group of 1000 sitefaithful individuals remained at their initial location, and the other group of 1000 were free-roaming, making steps in random directions every $10 \mathrm{~min}$, and moving at a speed of $1.4 \mathrm{~m} \mathrm{~s}^{-1}$ (selected as this equates with high-speed movement of harbour porpoises; Otani et al. 2001).

\section{Harbour porpoise and explosions on the DCS}

\section{Estimating harbour porpoise spatial distribution}

The defined 1 yr study period was 15 March 2010 to 15 March 2011; data on explosions and harbour porpoise numbers on the DCS were analysed for this period. We used data from 4 aerial surveys of porpoise abundance, conducted on the DCS in March, July and October-November 2010, and March 2011 (Scheidat et al. 2012, Geelhoed et al. 2013). Observers located at bubble windows on either side of the aircraft relayed details on environmental conditions (i.e. sea state, turbidity, cloud cover, precipitation and 'subjective' conditions) and sightings to a navigator. Sightings data included species, inclination angle (to estimate distance), group size, presence of calves, behaviour, swimming direction and cue (e.g. body at surface, under water, splash). Only data collected under good and moderate weather conditions (i.e. no heavy or freezing rain, visibility $>3 \mathrm{~km}$ and sea state $\leq 3$ Beaufort) were used in the analysis.

To correct for the number of undetected porpoises (i.e. those well below the surface or not noticed by the observer), we used published 1-sided effective strip width (ESW) estimates (Scheidat et al. 2008). 
The ESWs were derived using the distance sampling technique (Buckland et al. 2004) and the 'racetrack' method, which estimates the proportion of animals re-sighted after flying a circle and resurveying part of the transect line (Hiby \& Lovell 1998). These ESWs of Scheidat et al. (2008) were based on harbour porpoise surveys in the North Sea, using similar survey methods as in the present study, and were $76.5 \mathrm{~m}$ $(\mathrm{SE}=37.2 \mathrm{~m}$ ) for good sighting conditions and $27 \mathrm{~m}$ $(\mathrm{SE}=13.9)$ for moderate sighting conditions. The effective area surveyed is the distance travelled multiplied by the 2-sided ESW.

Estimating the number of individuals exposed to sound requires species distribution estimates that can be overlaid with sound maps (e.g. McCarthy et al. 2011, Thompson et al. 2013b). Not all types of species distribution models are suitable for this purpose. For example, presence-absence models can yield biased estimates, whereas models based on count data provide estimates which are proportional to density (Aarts et al. 2012). To estimate the absolute number of individuals exposed, it is furthermore necessary to account for those individuals present, but not detected. This was achieved by incorporating the effective survey area, which accounts for the number of undetected individuals (see Hiby \& Lovell 1998, Buckland et al. 2004).

In this study, porpoise density for the entire study area was derived from the survey data. First, a regular $10 \mathrm{~km} \times 10 \mathrm{~km}$ grid was created, and the surveyed area and number of porpoise sightings within each grid cell were calculated. Grid cells with no survey effort resulted in missing values. Next a Bayesian spatial model was fitted to the data using integrated nested Laplace approximation (Rue et al. 2009). The number of sightings $(Y)$ in each grid cell $i$ were treated as negative binomial distributed counts (with a dispersion parameter of $\tau$ ), and the log of the effective area surveyed $\left(A_{i}\right)$ was treated as an offset. $A_{i}$ included the detection probability. Spatial correlation in the residuals $(u)$ was treated as a latent Gaussian random field using a 2-dimensional autoregressive correlation function of order-1:

$$
\begin{gathered}
Y_{i} \sim \operatorname{NegBin}\left(\lambda_{i,} \tau\right) \\
\lambda_{i}=\exp \left[\beta_{0}+\ln \left(A_{i}\right)+u_{i}\right]
\end{gathered}
$$

where $\lambda$ is the expected count and $\beta_{0}$ is the model intercept. Bayesian prior distributions for the parameters $\beta_{0}, \tau$ and $\rho_{x}$ and $\rho_{y}$ (the correlation parameters in $x$ and $y$ direction, respectively) were defined as Gaussian distributed variables with mean 0 and precision 0.0001. The model was used to estimate porpoise density for each grid cell within the DCS. We fitted models for each survey season to account for large seasonal differences in abundance and distribution. Linear interpolation between seasonal porpoise density estimates was used to estimate porpoise density in each grid cell on the date of each explosion.

\section{Underwater sound field estimates}

Information on the underwater explosions during 2010 and 2011, their location, timing, and sound propagation properties, are detailed by von BendaBeckmann et al. (2015). We considered all 88 explosions on the DCS between 15 March 2010 and 15 March 2011, which overlapped with the period for which porpoise density estimates were available. Underwater sound propagation of the explosions was modelled using the software module SOPRANO (Sertlek \& Ainslie 2014), which takes into account frequency-dependent reflection losses due to surface and bottom interactions, and attenuation by the water. Input data for estimating sound propagation includes spectral source level energy and depth of the explosion, bathymetry maps (resolution: $0.125^{\prime} \times$ 0.125 , source: EMODNET database, www.emodnethydrography.eu; geo-acoustical properties of the seabed, source: DINO database, www.dinoloket.nl/ en/dinoloket) and wind speed. Broadband SELs were calculated for the near-surface layer $(1 \mathrm{~m}$ from the surface) and the near-bottom layer (1 $\mathrm{m}$ from the bottom). We assumed that $50 \%$ of the porpoises were near the surface (between 0 and $2 \mathrm{~m}$ depth; Teilmann et al. 2013) and $50 \%$ were near the sea floor at the time of the explosion.

\section{Hearing loss thresholds}

The (masked) TTS onset level (estimated based on measured auditory evoked potentials for a harbour porpoise exposed to single airgun transients) was at

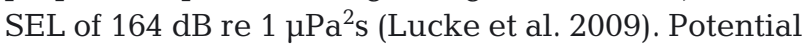
frequency-dependent effects of underwater explosions on TTS were assumed to be similar to the airgun transients, and therefore it was considered unnecessary to apply frequency weighting to the SEL when estimating TTS risk. No precise data are available on PTS-onset levels in marine mammals. Instead, following Southall et al. (2007), PTS-onset was

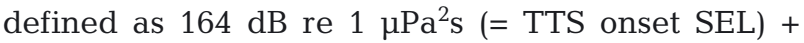
$15 \mathrm{~dB}=179 \mathrm{~dB}$ re $1 \mu \mathrm{Pa}^{2} \mathrm{~s}$, and considered a lower limit below which PTS is unlikely to occur. Experi- 
mental exposure of fresh dead marine mammal carcasses to underwater explosives (Ketten 2004) showed that ear trauma can occur at peak over-pressures between 10 and 25 psi (or 69-172 kPa), which corresponds to approximately SEL 190 to $203 \mathrm{~dB}$ re $1 \mu \mathrm{Pa}^{2} \mathrm{~s}$ for explosions in a shallow-water environment (von Benda-Beckmann et al. 2015). It was therefore assumed that the explosion sound would very likely cause PTS at the lower limit at which ear trauma occurs (i.e. SEL >190 dB re $1 \mu \mathrm{Pa}^{2}$ s), which is the PTS threshold used in this study.

Number of animals affected by single or multiple detonations: incorporating movement

For a single underwater explosion, the porpoise distribution map was overlaid with the corresponding SEL map of that explosion, to estimate which individuals were exposed to sound levels above the defined TTS or PTS thresholds (similar to von BendaBeckmann et al. 2015). Since explosions are impulsive, near-instantaneous sound sources, individuals are not capable of redistributing during the explosions. However, in-between explosions, individuals could redistribute. To estimate the cumulative number of unique individual porpoises exposed to all explosions within a year, we used the SEL map of the first explosion to define which individuals received TTS or PTS, and subsequently simulated porpoise movement during the time-window up to the next explosion. This was repeated for all explosions. Realistic individual-based movement models for harbour porpoises that incorporate resource dynamics in space and time have been developed (Nabe-Nielsen et al. 2013). However, the necessary porpoise movement data and a representation of the food landscape were not available to parameterize this model for the southern North Sea. Another harbour porpoise movement model was developed by Haelters et al. (2015), but this model assumed that porpoises actively avoided a pile-driving event. This assumption was not appropriate for the present simulation, as we aimed to examine movement when porpoises were not actively avoiding a sound source. Instead, we simulated movement for 2 extreme scenarios, sitefaithful and free-roaming porpoises.

Scenario 1: site faithful. Porpoise density estimates for each survey season were treated as probability density surfaces from which independent realizations of individual points (i.e. porpoises) were generated (see e.g. Fig. 5). At the mid-point between 2 successive surveys, each simulated individual from one survey was linked to the nearest individual from the subsequent survey. Since the absolute abundance between seasons differed, some individuals could not be linked, and those were considered to be temporarily outside the study area. The SEL sound maps of each explosion were then linked to the realized distribution of individual animals derived from the aerial survey closest in time.

Scenario 2: free roaming/high mobility. Although in this simulation we only considered the impact of explosions on porpoises within the DCS, we allowed porpoises to move freely within the entire North Sea. The total North Sea population size was defined as the sum of the geographic areas B, H, J, L, M, T, U, $\mathrm{V}$ and Y of Hammond et al. (2013), which equates to 232450 animals. Since no information was available on annual changes in abundance, the population size was assumed to remain constant between 2010 and 2011. Although these 232450 individual animals were allowed to move freely within the entire North Sea, the total abundance and distribution of animals within the DCS corresponded to our absolute, seasonal porpoise density estimate. This was achieved by assigning to each. grid cell outside the DCS, but within the North Sea, a sampling probability of $\left(232450-N_{s}\right) / G$. Here, $N_{s}$ is the total abundance within the DCS for season $S$, and $G$ is the total number of grid cells in the entire study area.

For the first explosion, the simulated distribution of porpoises was based on the nearest survey in time, similar to Scenario 1 above. Between the explosion at time $t 1$ and the subsequent explosion at time $t 2$, the individual animal was allowed to move at an average cruising speed of $v=1.4 \mathrm{~m} \mathrm{~s}^{-1}$ over a maximum distance of $m=v(t 2-t 1)$. Here, $v$ is the speed at which the energetic cost of transportation is minimised (1.3-1.5 $\mathrm{m} \mathrm{s}^{-1}$ ). This lies between the mean (experimentally derived) swim speed $\left(0.76-0.91 \mathrm{~m} \mathrm{~s}^{-1}\right)$ and maximum observed swim speed $\left(4.2 \mathrm{~m} \mathrm{~s}^{-1}\right.$ ) (Otani et al. 2001). For each individual porpoise at $t 1$, the porpoise density map corresponding to the explosion at $t 2$ was used to generate a new point location, with the constraint that it was within the maximum travel distance $m$.

These 2 simulations allowed us to trace how individual modelled animals (i.e. points) were exposed to multiple explosions in time. No data are available on porpoise response to underwater explosions, and it is even questionable whether they are capable of estimating the distance or direction of the source. Hence, no attempt was made to study the effect of avoidance. 


\section{RESULTS}

\section{Pilot simulation: effect of movement of the animal and sound source on sound exposure}

In the pilot simulation for a fictional animal, when the sound source remained at a fixed location and animals were site-faithful (Fig. 1d), only those
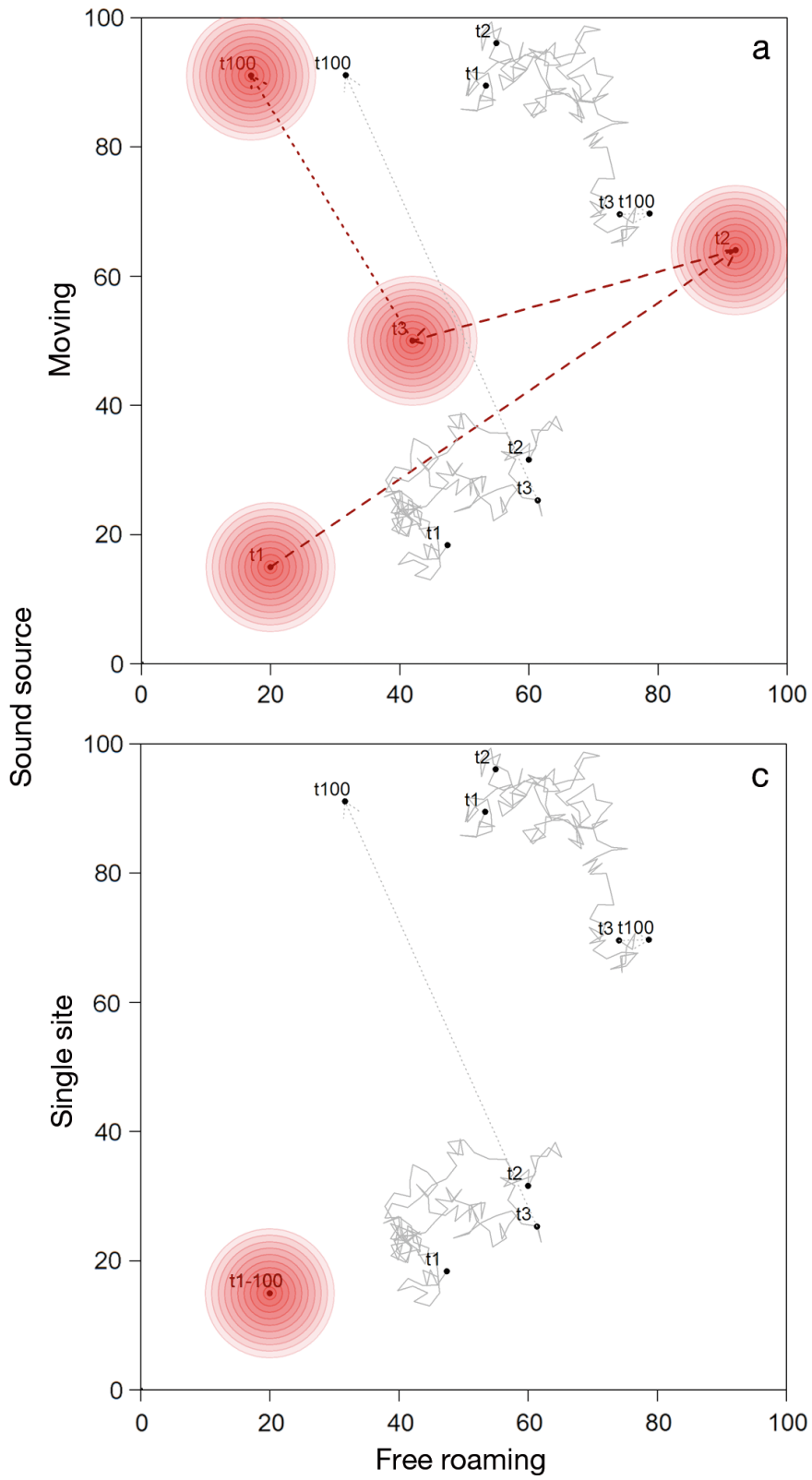

individuals living directly within the impact zone (here $<10 \mathrm{~km}$ from the source) were negatively impacted (Fig. 2a); however, they were exposed 100 times, i.e. each time the sound source was active (Fig. 2b). In contrast, when animals were freeroaming and did not avoid the impact area, nearly all individuals (on average 937 of 1000) were exposed at least once, and on average each was
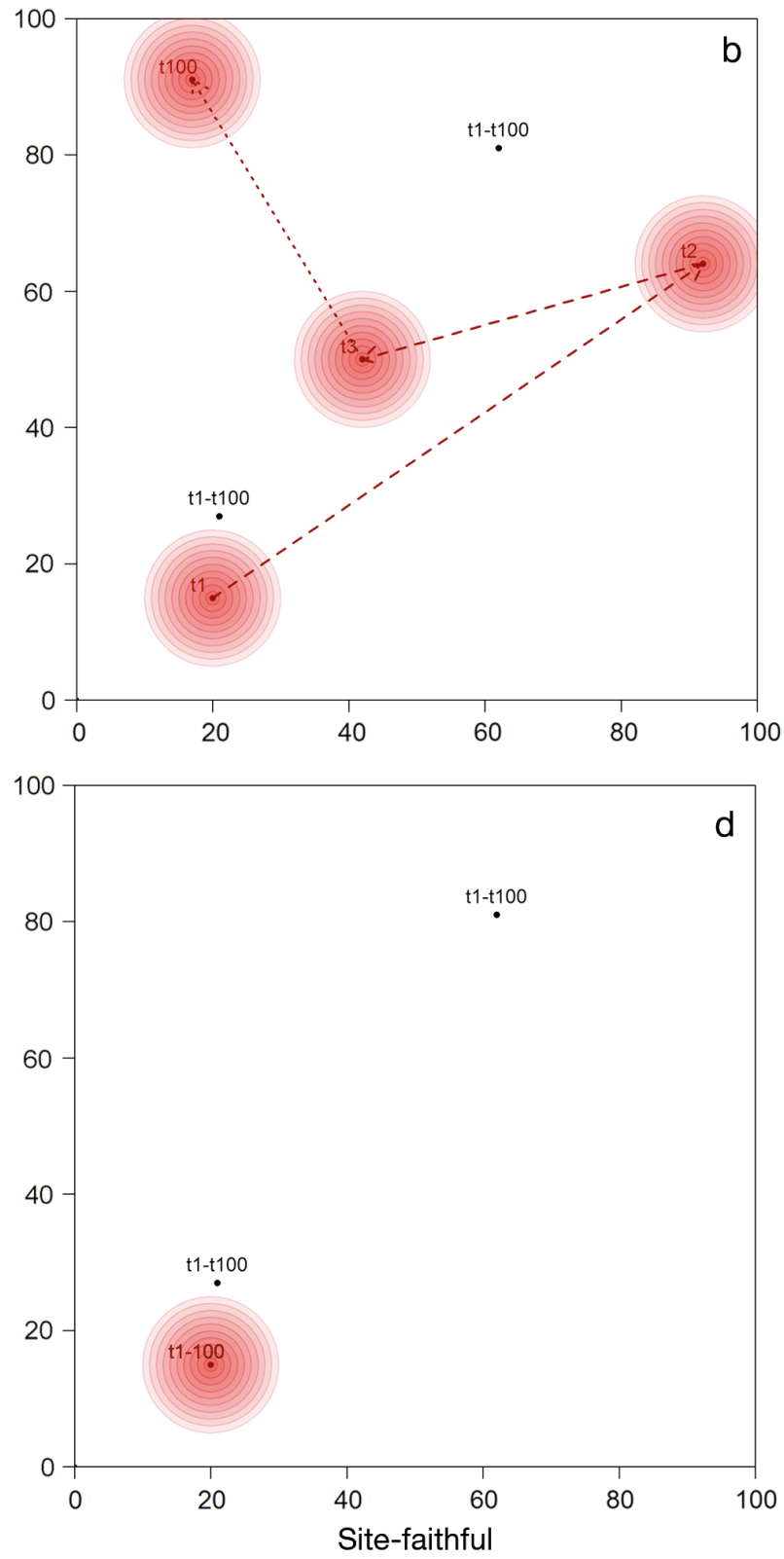

\section{Animal}

Fig. 1. Illustrations from a simulation of the movement by a fictional animal and a sound source, which occurs once per day over a 100 d period $(\mathrm{t} 1$ = sound emitted on Day 1, t100 = sound emitted on Day 100). The sound source (red circle) either $(\mathrm{a}, \mathrm{b})$ moved randomly through space or $(\mathrm{c}, \mathrm{d})$ remained at 1 location. Animals (grey track and black dots) either moved at a speed of $1.4 \mathrm{~m} \mathrm{~s}^{-1}$ randomly through space $(\mathrm{a}, \mathrm{c})$ or were site-faithful $(\mathrm{b}, \mathrm{d})$. Only 2 animal tracks and sound locations during the first $3 \mathrm{~d}$ and at $\mathrm{t} 100$ are shown 

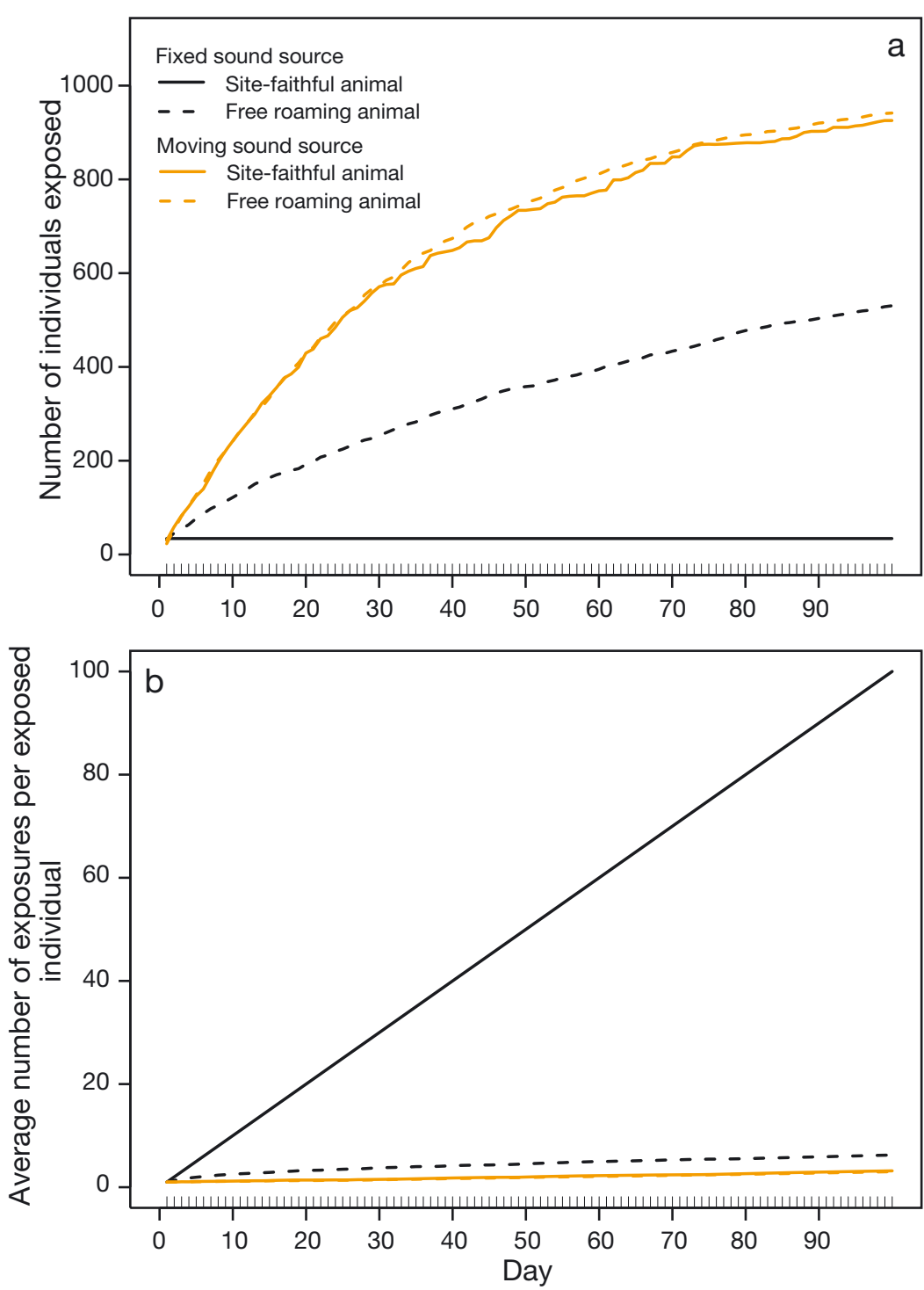

Fig. 2. Simulation illustrating the effect of movement by an animal and a sound source on exposure probability. (a) When an animal is free-roaming and the sound source is at a predictable (i.e. fixed) location, the cumulative number of individuals impacted is much larger than when the animal is sitefaithful, although (b) the number of repeated exposures is reduced. If the location of the source is completely unpredictable in space, movement does not reduce the number of individuals exposed (a) or the average exposure probability (b)

\section{Spatiotemporal distribution of harbour porpoises and explosions on the DCS}

Explosives were mostly detonated at their site of discovery, with the highest density being in the southern part of the DCS (Fig. 3). Most of the explosives were dropped in this area during WWII (OSPAR Commission 2010). The detonations occurred in all months of the year, with a peak in March. There were 88 explosions on the DCS between 15 March 2010 and 15 March 2011.

Harbour porpoise distribution over the DCS changed between each survey (Fig. 4; for a summary of fitted models, Table S1 in the Supplement at www.intres.com/articles/suppl/m557p261_supp. pdf). In March 2010 (Fig. 4a), the average porpoise density was $1.09 \mathrm{~km}^{-2}$, with the highest density in the central DCS and the lowest density in the southern DCS. There was no survey effort in the most northern Dogger Bank region, so those density estimates were extrapolated from densities in the adjacent region B. In July 2010 (Fig. 4b), porpoises were present in low numbers, averaging $0.60 \mathrm{~km}^{-2}$. In OctoberNovember 2010 (Fig. 4c), overall density was again low $\left(0.63 \mathrm{~km}^{-2}\right)$. In March 2011 (Fig. 4d), the overall density was high (i.e. $1.34 \mathrm{~km}^{-2}$ ). The model-based estimates of harbour porpoise numbers on the DCS were 64851 (March 2010), 35754 (July 2010), 37574 (OctoberNovember 2010) and 79318 (March 2011). These estimates were within the $95 \%$ confidence intervals of the original stratified survey estimates of Geelhoed et al. (2013). exposed 3 times during the $100 \mathrm{~d}$ study period. The total number of impact events was the same, regardless of whether individuals were site-faithful or free-roaming.

When simulating a sound source which moved randomly (Fig. 1a,c), different movement behaviours had little effect on either the numbers of individuals exposed or numbers of multiple exposures. After the 100 sound events, approximately all individuals were exposed at least once.

\section{Estimated number of porpoises affected by single explosions}

There was considerable variation in the number of harbour porpoises affected by each explosion. These estimates were influenced by the assumed position of harbour porpoises in the water column: if near the sea floor, the exposure was approximately 8 times larger compared to near the surface (Table S2 in the Supplement, von Benda-Beckmann et al. 

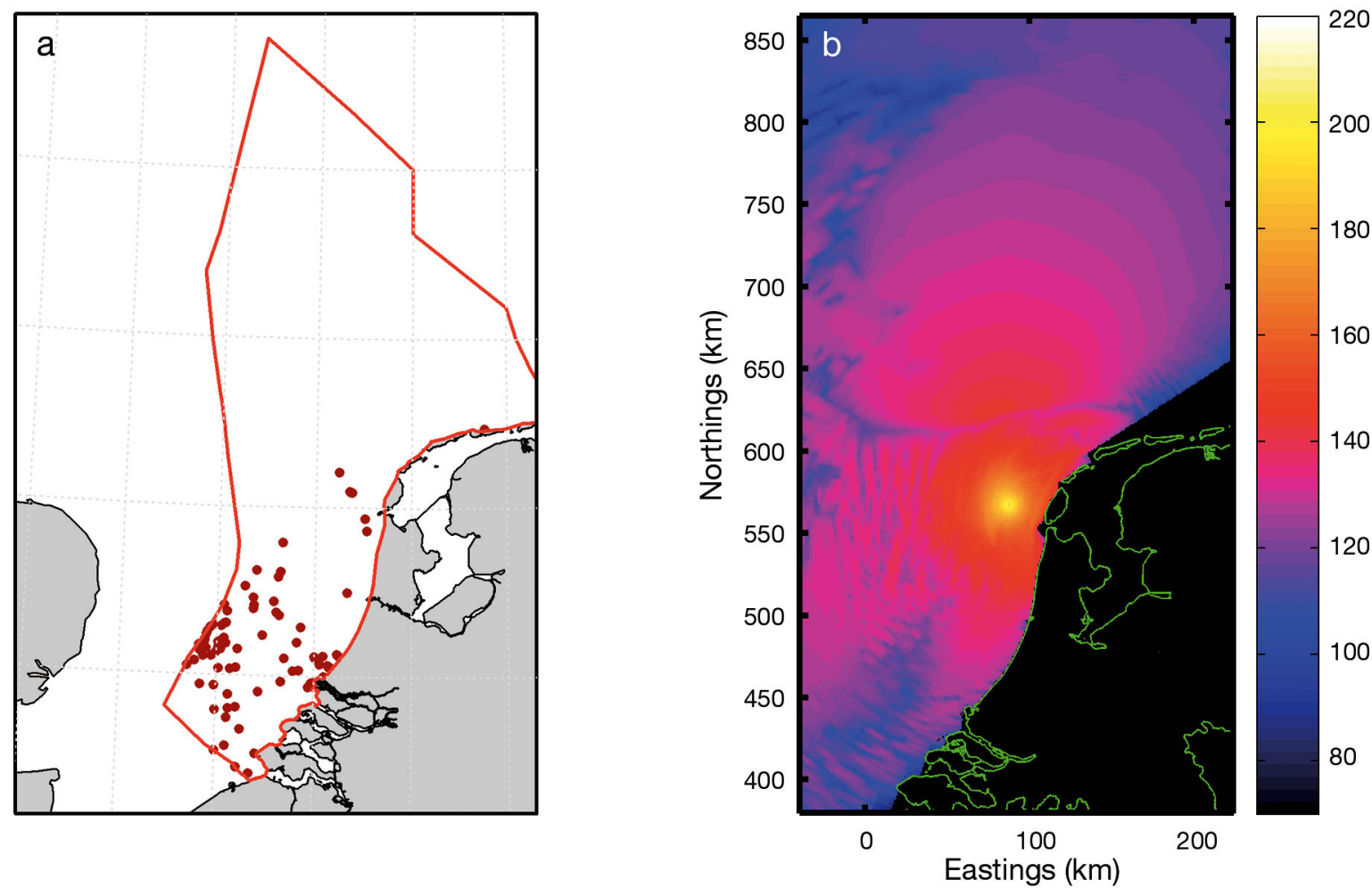

Fig. 3. (a) Distribution of explosives detonated by the Royal Netherlands Navy in 1 yr (15 March 2010 to 15 March 2011). (b) Example of an estimated unweighted broadband sound exposure level (SEL dB re $1 \mu \mathrm{Pa}^{2} \mathrm{~s}$ ) of a single explosion (263 TNT eq. charge mass) received at a depth of $1 \mathrm{~m}$ above the sea floor. See von Benda-Beckmann et al. (2015) and Sertlek \& Ainslie (2014) for more details

2015). On average, for each single explosion within the DCS during the survey period, 15 porpoises were estimated to have received an SEL of $\geq 190 \mathrm{~dB}$

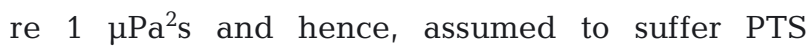
(Table S2). At the lower threshold limit of the range at which PTS becomes increasingly likely (i.e. SEL $\geq$

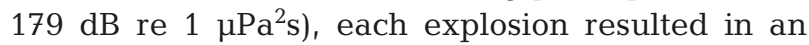
average of 62 porpoises suffering PTS (Table 1). On average, following each explosion, 319 porpoises were estimated to have been exposed to a SEL of

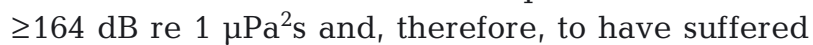
a TTS (Table S2).

\section{Estimated number of porpoises affected by multiple explosions: effect of porpoise movement}

The average time between explosions was $3.8 \mathrm{~d}$ (median $=0.8, \mathrm{SD}=6.6)$, during which individuals were often able to redistribute. For the continuous roaming scenario, assuming a maximum average cruising speed of $1.4 \mathrm{~m} \mathrm{~s}^{-1}$ (Otani et al. 2001), individuals were theoretically capable of travelling $120 \mathrm{~km}$ within a single day (i.e. $24 \mathrm{~h}$ ). Assuming non-directional, random movement in-between successive explosions, some individuals remained in the proximity of the site of the previous explosion, while others relocated to regions tens of $\mathrm{km}$ away. If the time-window between successive explosions was sufficiently large, individuals were capable of relocating to any site within the DCS or even beyond (Fig. 5a-c). In contrast, site-faithful individuals (by definition) remain at their initial fixed location (Fig. 5d-f) and are exposed to successive explosions when the following (subsequent) explosions were in the vicinity.

For a single year (March 2010 to March 2011), there were 1283 estimated PTS events (i.e. PTS very likely, SEL $>190 \mathrm{~dB}$ re $1 \mu \mathrm{Pa}^{2} \mathrm{~s}$ ). When porpoises were freeroaming throughout the North Sea, $0.5 \%$ of the exposed individuals were exposed at least twice, while for site-faithful individuals it was $6 \%$ (Fig. 6c,d, Table 1).

On average, 28067 TTS events were estimated to occur on the DCS during the study period. If porpoises roamed freely within the entire North Sea, an estimated 24272 unique individuals experienced TTS, and approximately $10 \%$ of these ex- 


\section{Mar 2010}

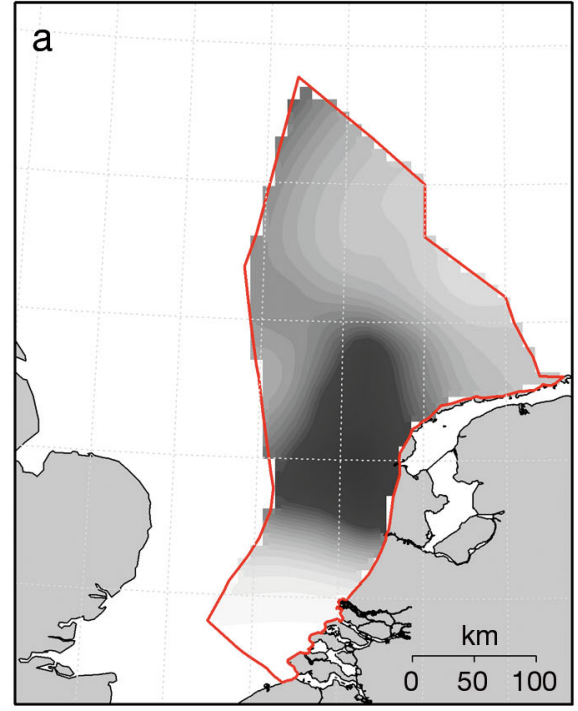

Oct/Nov 2010

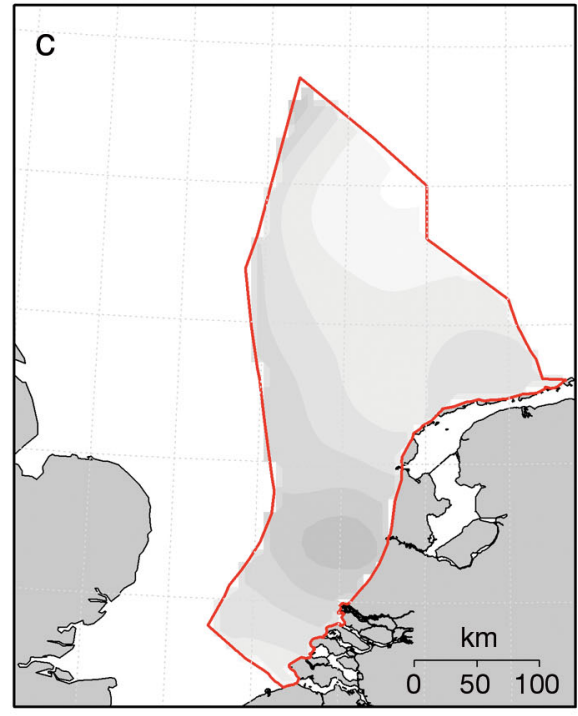

Jul 2010

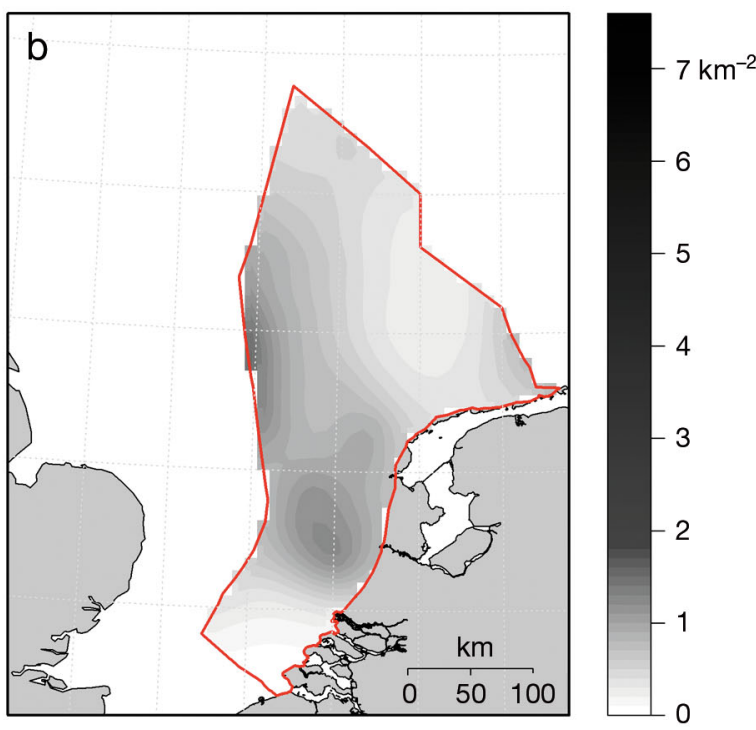

Mar 2011

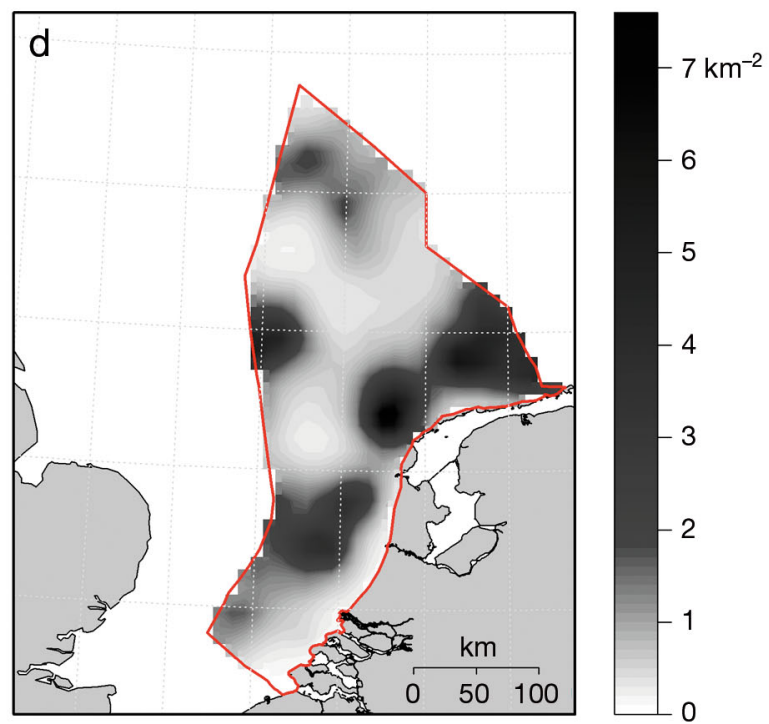

Fig. 4. Seasonal model-based estimates of harbour porpoise Phocoena phocoena density (grey scale) within the Dutch Continental Shelf (red polygon) for (a) March 2010, (b) July 2010, (c) October-November 2010, and (d) March 2011 based on aerial surveys during those periods (Geelhoed et al. 2013)

perienced TTS on multiple occasions. In contrast, when individuals were site-faithful, only 14963 experienced TTS, but did so on multiple occasions (38\%; Table 1, Fig. 6a,b). We also estimated the cumulative number of porpoises exposed to sound from underwater detonations, assuming porpoises were uniformly distributed in space (Fig. S1 in the Supplement). More individuals experienced TTS and PTS. This is because the observed porpoise distribution (based on the aerial survey data) is on average lower in the region where most detonations occur (Figs. $3 \& 4$ ).

\section{DISCUSSION}

\section{Effect of movement on the number of harbour porpoises exposed to sound}

The results from the pilot simulation showed that increased movement speed and rate of dispersal could increase the number of individuals within a population that would be exposed to a repetitive anthropogenic sound. However, the repeated exposure probability was reduced. This effect was strongest if the sound source remained at a fixed location. 

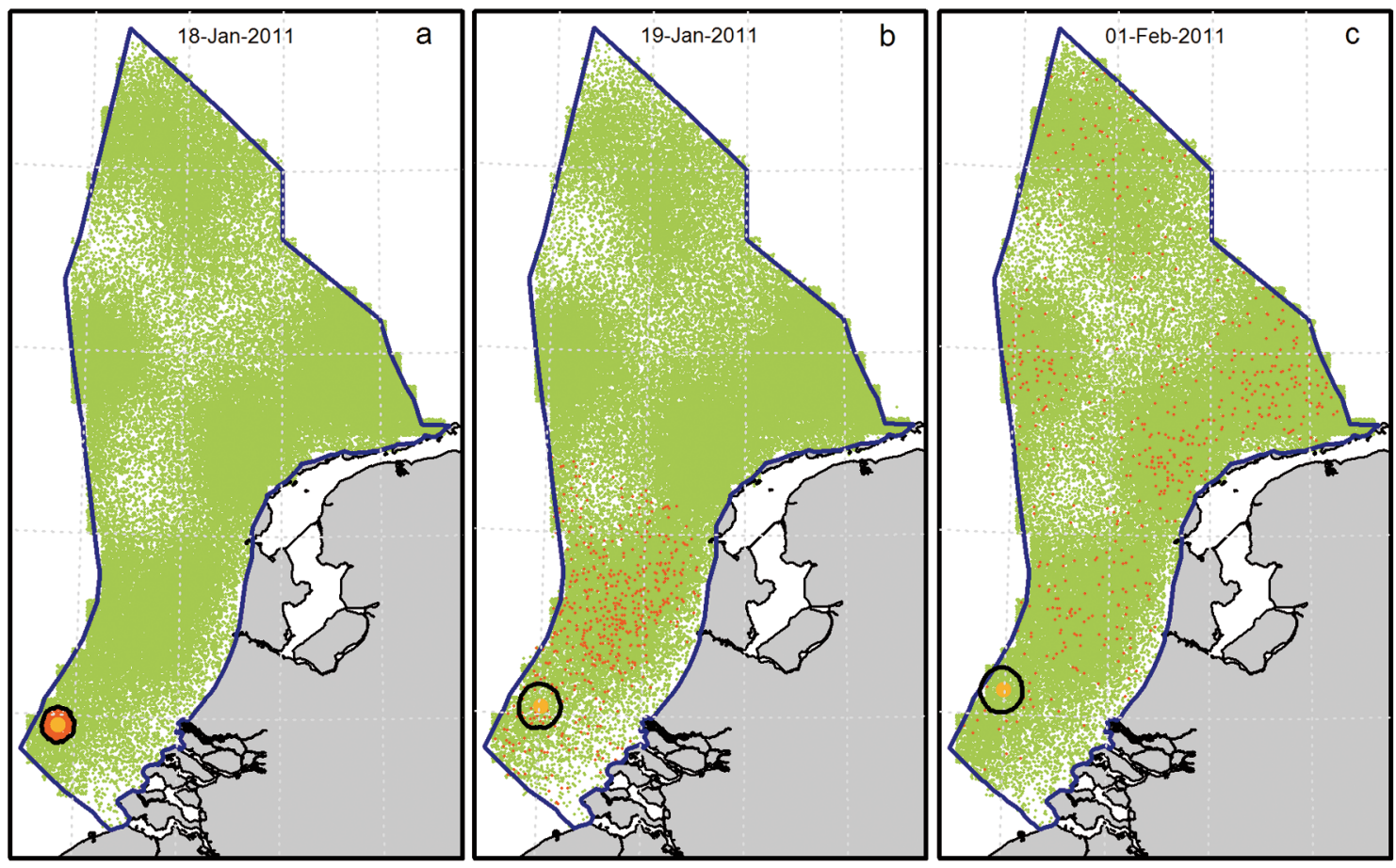

Free roaming
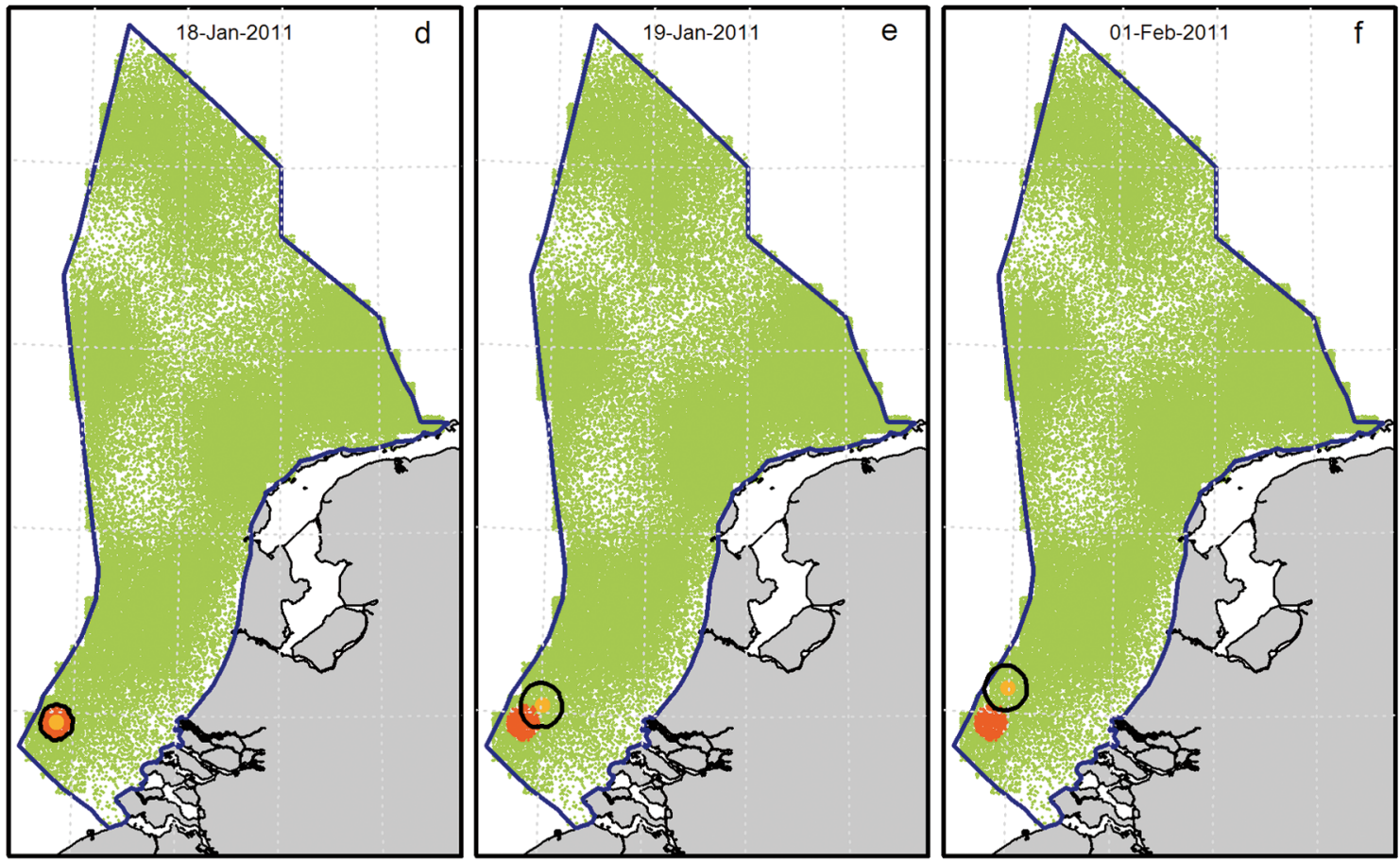

Site faithful

Fig. 5. Example of model results showing the effect of harbour porpoise Phocoena phocoena movement (a-c: free-roaming; d-f: site-faithful) on repeated exposure probability to successive underwater explosions. The 79000 green and red points represent all individual porpoises; their distributions are derived from seasonal density surface estimates. Red points are those individuals exposed to a sound exposure level (SEL) $\geq 164 \mathrm{~dB}$ re $1 \mu \mathrm{Pa}^{2}$ s, i.e. they experienced a temporary threshold shift (TTS; black circle), from an explosion on 18 January 2011. Free-roaming individuals were capable of dispersing to other regions. With explosions occurring near each other, amongst the individuals affected by the first explosion, free-roaming individuals had less chance of multiple exposures than did site-faithful individuals 
TTS (164 dB re $\left.1 \mu \mathrm{Pa}^{2} \mathrm{~s}\right)$

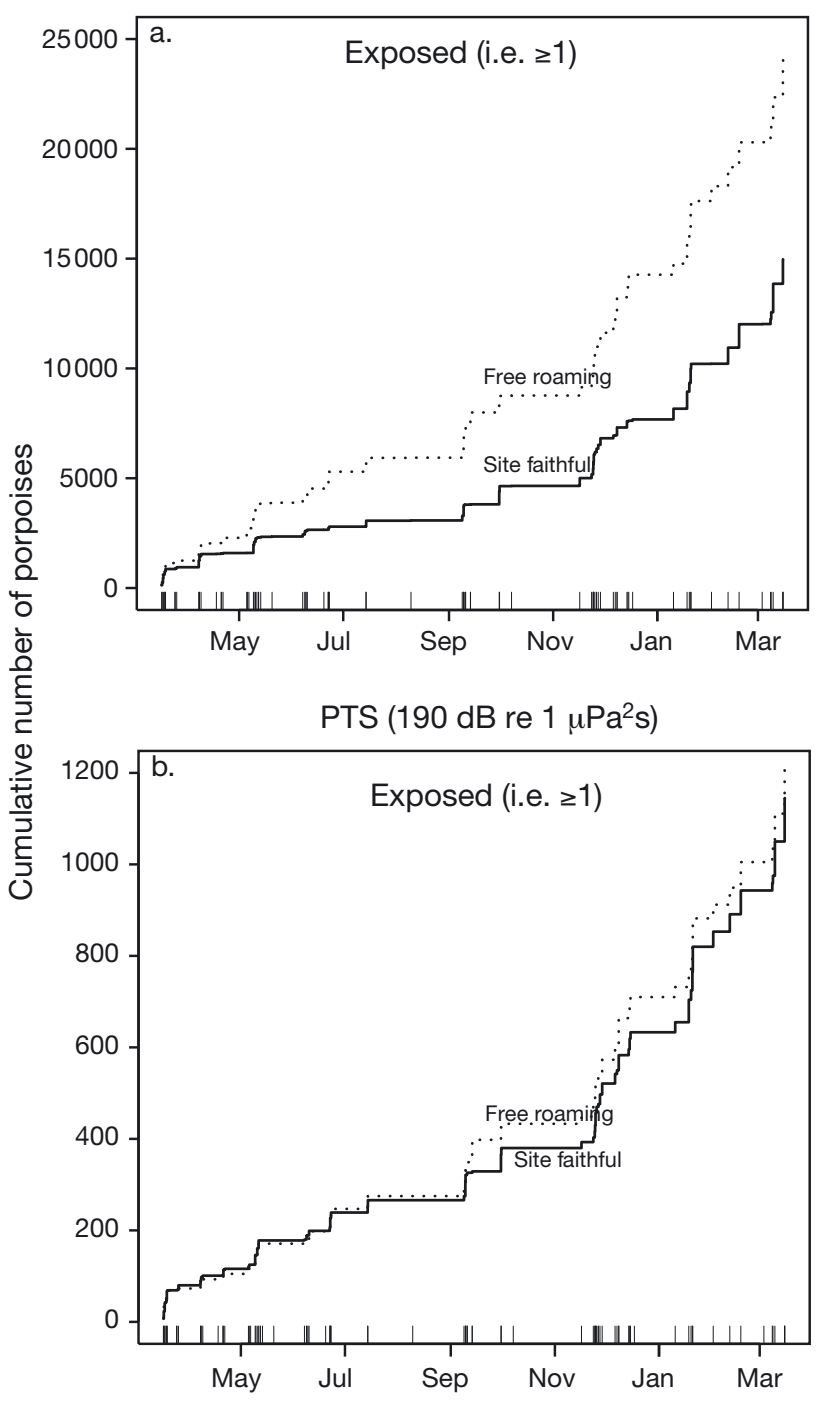

TTS (164 dB re $\left.1 \mu \mathrm{Pa}^{2} \mathrm{~s}\right)$
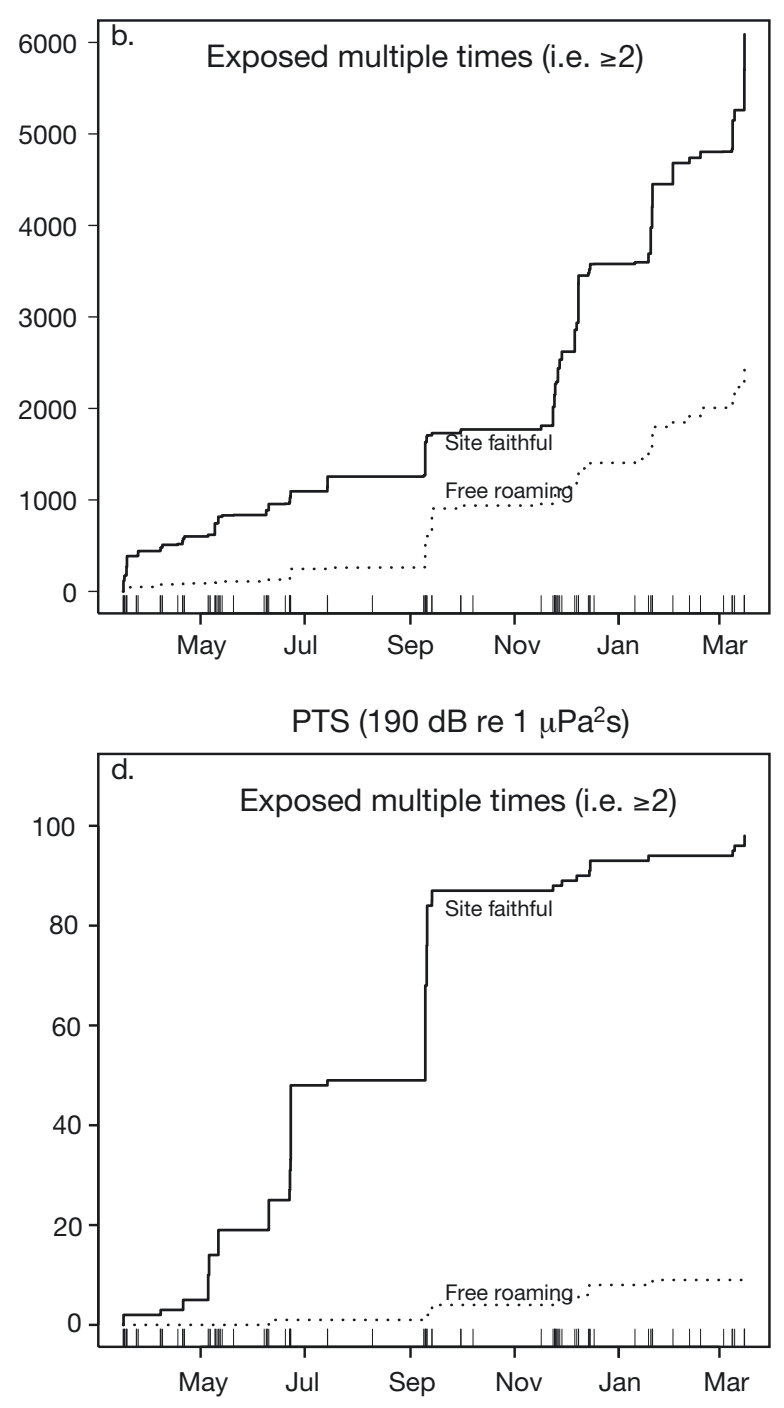

Date (2010-2011)

Fig. 6. Effect of movement type (high site fidelity versus free-roaming throughout the North Sea) on the number of individuals expected to very likely experience onset of $(a, b)$ temporary threshold shift (TTS; sound exposure level, SEL $\geq 164 \mathrm{~dB}$ re $1 \mu \mathrm{Pa}{ }^{2} \mathrm{~s}$ ) or (c,d) permanent threshold shift (PTS; SEL $\geq 190 \mathrm{~dB}$ re $\left.1 \mu \mathrm{Pa}^{2} \mathrm{~s}\right)$ at least once $(\mathrm{a}, \mathrm{c})$ and at least twice (b,d). Free-roaming movement will lead to more individuals being exposed to levels exceeding TTS (and PTS) thresholds, but high site fidelity leads to more individuals being exposed multiple times

Since most marine mammal species, including harbour porpoises, are highly mobile, incorporating the effect of movement is important for estimating the proportion of the population exposed.

Even for underwater explosions, which may appear unpredictable in space and time, the cumulative number of harbour porpoises exposed depended on how individuals moved. We estimated that if all individuals were free-roaming and continuously on the move, in a single year on the DCS, 1200 individuals were very likely ( $>95 \%$; see von Benda-Beckmann et al. 2015) to experience PTS and an estimated 24000 individuals would experience TTS. This equates to 0.5 and $10 \%$, respectively, of the estimated North Sea population. In contrast, if harbour porpoises were site-faithful, fewer individuals would experience PTS or TTS (i.e. 1100 [0.47\%] and 15000 [6.5\%], respectively), but more would be exposed on multiple occasions. These numbers were probably underestimates, since only porpoises on the DCS were considered (this was the available survey data), and many individuals outside the DCS were probably also exposed. In addition, porpoises residing within the DCS might have been affected by detonations out- 
Table 1. Estimated number (95\% confidence intervals in brackets) of harbour porpoises Phocoena phocoena suffering partial hearing loss due to the cumulative effect of 88 explosive clearances on the Dutch Continental Shelf (DCS) between 15 March 2010 and 15 March 2011. Porpoises were assumed to spend $50 \%$ of the time near the surface and $50 \%$ near the bottom. Given the lack of empirical data on temporary (TTS) and permanent threshold shift (PTS) values for underwater explosions, the terms 'very likely' (probability exceeding 0.95) and 'increasingly likely' (between 0.05 and 0.95 probability) were used. See von Benda-Beckmann et al. (2015) for more details. SEL: sound exposure level

\begin{tabular}{|lcrr|}
\hline \multirow{2}{*}{ Type } & $\begin{array}{c}\text { Threshold unweighted SEL } \\
\left(\mathrm{dB} \text { re } 1 \mu \mathrm{Pa}^{2} \mathrm{~s}\right)\end{array}$ & \multicolumn{2}{c|}{ Number of unique porpoises } \\
\cline { 3 - 4 } & 203 & $59(46-76)$ & $50(38-66)$ \\
Blast wave ear trauma very likely & 190 & $1217(1151-1287)$ & $1145(1081-1213)$ \\
PTS very likely & 179 & $5204(5066-5346)$ & $4275(4152-4401)$ \\
PTS increasingly likely & 164 & $24272(23985-24562)$ & $14963(14748-15180)$ \\
TTS very likely & &
\end{tabular}

side the DCS, for which no complete data on detonation activities were available.

The effect of different movement behaviours on the total number of animals experiencing PTS was small, because the PTS effect area was small (relatively to that for TTS), and very few explosions occurred exactly in the same spot. In contrast, the number of individuals exposed to SELs exceeding the TTS threshold in the free-roaming scenario was 1.6 times higher than in the site-faithful scenario. While movement altered the balance between the number of individuals exposed and the number of repeated exposures, it did not influence the number of impact events, at least assuming individuals did not actively avoid the region where they were previously exposed.

\section{Avoid and redistribute once exposed?}

The pilot simulation showed that if the location of a sound source was fixed, an animal remaining sitefaithful increased its risk of being exposed multiple times. Conversely, if the location of the source was unpredictable, any type of movement by the animal, including high site-fidelity or active avoidance, had no effect on numbers exposed and repeated exposure probability.

The simulation study on harbour porpoises exposed to underwater explosions also revealed that sitefaithful porpoises had a higher risk of suffering TTS or PTS on multiple occasions than did free-roaming porpoises (Fig. 6). This suggests the explosions were not evenly distributed, and individuals that did not move away from the area following an explosion were at a higher risk of future injury. Indeed, in this study explosions were more densely distributed in 1 region, the southern DCS (Fig. 3). Dense clustering of human sounds is often likely, as human activities tend to remain in an area for a period rather than be evenly distributed over space or time. For example, prior to construction of an offshore wind farm, the area is intensively surveyed for underwater explosives, which are then detonated in situ. Although not explicitly explored in this study, harbour porpoise density was lower in the southern DCS than over the rest of the DCS (Fig. 4). This distribution may have resulted from natural processes (e.g. uneven prey availability) or other anthropogenic activities (e.g. the intensive shipping activity near the international harbour of Rotterdam). It may also have been influenced by the relatively high intensity of underwater explosions in the region. Unpublished records from the Royal Netherlands Navy suggest that explosions have been concentrated in the DCS over several years. If harbour porpoises fled from explosions and avoided the areas in future, this in itself could account for the lower numbers in the southern DCS. Aerial surveys, GPS tracking of individual animals or passive acoustic monitoring prior to and after planned detonations of explosives could be used to test this (for a suggested experimental set-up, see e.g. Dähne et al. 2013 or Tougaard et al. 2015).

Several anthropogenic activities emit repetitive sounds separated by silent periods. During the silent periods, if sufficiently long, acoustically naive marine animals can enter the area where there would be a high risk of auditory (or other physical) injury. Such entry into an area of risk is more likely to occur for highly mobile animals. Hence, although movement allows animals to avoid recognised areas of risk, it can increase the risk of being exposed to high level, intermittent sound sources.

Whether individuals are expected to avoid an area once exposed to an intense sound source ultimately depends on how well the individual is capable of predicting when and where a new sound will be emitted. Even if the individual would have perfect knowledge of the spatial location and timing of the sound 
event, it is questionable whether avoidance is the best option. Avoidance may reduce future auditory damage, but it also reduces the time and the amount of habitat available in which to forage or reproduce. Clearly decisions about whether to move and/or avoid certain areas are complex and difficult to predict, particularly for species in which high levels of individual variability can be expected, such as for marine mammals.

\section{Importance of movement data for assessing the impact of repetitive sound exposures}

Given the importance of movement patterns on the total number of individuals impacted, species distribution models producing a single distribution estimate (see e.g. Fig. 4) might be sufficient to estimate impact for a single event, such as a single explosion. However, they would be insufficient for assessing the impact of longer-lasting human activities, including a series of explosions, seismic surveys, pile-driving and shipping operations. Particularly for highly mobile species, the time spent (or population density) at a specific location can be low. Nevertheless, if the sites are vital for the species' survival and reproduction (e.g. movement corridors), the cumulative number of individuals using the site might be high (van Horne 1983). Hence, for longer-lasting activities (e.g. piledriving or seismic surveys), the cumulative number of individuals impacted would far exceed the instantaneous or average density in the vicinity. The functional form of this accumulation depends on how individuals move. Such individual movement data are often unavailable for marine mammal species (including for harbour porpoises in the southern North Sea). As an alternative, simulations can provide information on the magnitude of the effect of movement on the number of individuals exposed and exposure probability to specific anthropogenic sound sources.

The simulation of harbour porpoise movement in response to explosions demonstrated that for PTS, the type of movement had little impact on the estimated number of individuals suffering PTS. In contrast, for more moderate exposure impacts with larger impact areas (e.g. TTS; Fig. 6), the type of movement behaviour had a substantial impact on the number exposed. As the initiation of behavioural response could be triggered at larger distances than the PTS and TTS threshold distances, movement behaviour was likely to have an even greater influence on total numbers impacted than suggested by our results. The availability of actual movement data and obser- vations of responses at larger distances are critical to better understanding the magnitude of impacts from anthropogenic sounds.

\section{From number of individuals impacted to population-level consequences}

Most applied studies on the impact of sound on marine organisms ultimately attempt to estimate how specific anthropogenic activities impact the vital rates of members of a population. This involves a series of analysis steps, often referred to as the PCoD framework (e.g. see King et al. 2015). One step involves estimating which and how many individuals are exposed to high sound levels, and this has been the main focus of our study: How many individuals of the North Sea harbour porpoise population are exposed to sound from underwater explosions and, as a consequence, are expected to have PTS or TTS? However, whether PTS or TTS leads to a significant decrease in vital rate parameters (i.e. survival, growth and reproduction) remains unresolved. For this, species-specific studies that assess how hearing impairments or particular noises reduce foraging efficiency (e.g. Shafiei Sabet et al. 2015 for captive zebrafish), communication and reproduction are urgently needed.

\section{Further research}

Although the framework presented here illustrates how to estimate the number of individuals exposed to potentially harmful anthropogenic sounds, and suggests that underwater explosions may impact a substantial part of the North Sea harbour porpoise population (Fig 6, Table 1), a number of improvements in the estimates can be made. First of all, various fundamental biological and especially auditory parameters should be evaluated, such as the SEL at which PTS starts to occur and which hearing frequencies are affected or lost (see also von Benda-Beckmann et al. 2015). Similarly for TTS, the extent of the threshold shift, the duration and frequency range affected are completely unknown. Furthermore, although this study provides clues about how different movement regimes influence the total number of unique exposed individuals, no data are currently available on harbour porpoise movement within the southern North Sea. Movement studies in the Kattegat-Skagerrak area of Denmark suggest that porpoises mix local searching/site fidelity movements with larger-scale movements (Nabe-Nielsen et al. 2013). Land- and 
ship-based surveys in coastal habitats often reveal large tide-dependent variability in occurrence, which suggests that at least in these habitats, porpoises do not remain at a single site (Jones et al. 2014, IJsseldijk et al. 2015). In the North Sea, seasonal differences in coastal sighting rates (Camphuysen 2011) and absolute abundance estimates (Geelhoed et al. 2013, this study) suggest that longdistance migrations also occur seasonally. Several direct observations provide further detail on the flexibility in movement by harbour porpoises. In one example, an albino porpoise observed in Den Helder on 25 February 2012 at 11:30 h was re-sighted near Juist (Germany) on 28 February at 15:30 h, a distance of $187 \mathrm{~km}$ travelled in just $76 \mathrm{~h}$, implying a minimum average speed of $\sim 0.7 \mathrm{~m} \mathrm{~s}^{-1}$ (C. Rebel \& K. Camphuysen pers. comm.). In contrast, a female porpoise with a calf was observed to remain present near an offshore oil platform for at least $3 \mathrm{wk}$ (Camphuysen \& Krop 2011), indicating a high level of temporal site fidelity. Such anecdotal information suggests that porpoise movement and dispersal rate may vary between seasons and between individuals. Therefore, a model that has a range of options for each porpoise, as well as a seasonal 'migration' pattern and inter-annual variability, might provide impact estimates that come closer to reality.

In addition to the lack of data on how porpoises move under 'natural' circumstances, it is unknown how porpoises respond to underwater explosions. Harbour porpoises do respond with avoidance behaviour to persistent sound (Dähne et al. 2013, Tougaard et al. 2015), but behavioural reactions to one-off explosions are unknown. They could involve brief startles, or periods of erratic, fast swimming, followed by directional swimming for long periods (minutes to hours, depending on the strength of the sound and previous experience, and the distance between the sound source and the porpoise during onset). Although the animals are unlikely to be capable of determining the source direction for such a single short-duration sound (Kastelein et al. 2007), persistent swimming over several kilometres by exposed harbour porpoises may still lead to lower densities within the impact areas.

If porpoises in the southern North Sea move large distances on a daily basis and have no spatial knowledge regarding the location of upcoming detonations, impact areas may soon be replenished. The study by Thompson et al. (2013a) showed that after short-term (75-150 min) disturbance (by a seismic survey), harbour porpoise density returned to initial values within a few hours, and it was argued that therefore the activity did not lead to long-term displacement of porpoises. That study, however, was based on passive acoustic monitoring and visual aerial surveys. Without individual movement data, it is not possible to distinguish between a situation where displaced individuals returned, or the impacted area was replenished by naïve individuals that were not aware of the former acoustic disturbance. Hence, while observations on population density alone can be obscured by the behaviour of previously unexposed individuals, animal movement data reveal whether anthropogenic sound has long-term negative effects on individuals.

Acknowledgements. We thank the Netherlands Ministry of Defence for funding this study, and in particular LCdr René Dekeling for project guidance. The Netherlands Ministry of Defence and the KNMI kindly provided information on the reported explosion events. We thank the aerial observers and coordinators, particularly Hans Verdaat, for their effort. Michael Ainslie kindly provided feedback on an early version of the manuscript. H.Ö.S. and G.A. were funded by NWO-ZKO grant 'Effects of underwater noise on fish and marine mammals in the North Sea'.

\section{LITERATURE CITED}

Aarts G, Fieberg J, Matthiopoulos J (2012) Comparative interpretation of count, presence-absence and point methods for species distribution models. Methods Ecol Evol 3:177-187

Ainslie MA, de Jong CAF, Dol HS, Blacquière G, Marasini C (2009) Assessment of natural and anthropogenic sound sources and acoustic propagation in the North Sea. Rep No. TNO-DV 2009 C085. TNO Defence, Security and Safety, The Hague

Buckland ST, Anderson DR, Burnham KP, Laake JL, Borchers DL, Thomas L (2004) Advanced distance sampling. Oxford University Press, New York, NY

Camphuysen CJ (2011) Recent trends and spatial patterns in nearshore sightings of harbour porpoises (Phocoena phocoena) in the Netherlands (Southern Bight, North Sea), 1990-2010. Lutra 54:39-47

Camphuysen CJ, Krop A (2011) Maternal care, calf-training and site fidelity in a wild harbour porpoise in the North Sea. Lutra 54:123-126

Dähne M, Gilles A, Lucke K, Peschko V and others (2013) Effects of pile-driving on harbour porpoises (Phocoena phocoena) at the first offshore wind farm in Germany. Environ Res Lett 8:025002

Geelhoed SCV, Scheidat M, van Bemmelen RSA, Aarts G (2013) Abundance of harbour porpoises (Phocoena phocoena) on the Dutch Continental Shelf, aerial surveys in July 2010-March 2011. Lutra 56:45-57

Haelters J, Dulière V, Vigin L, Degraer S (2015) Towards a numerical model to simulate the observed displacement of harbour porpoises Phocoena phocoena due to pile driving in Belgian waters. Hydrobiologia 756:105-116

Hammond PS, Macleod K, Berggren P, Borchers DL and others (2013) Cetacean abundance and distribution in 
European Atlantic shelf waters to inform conservation and management. Biol Conserv 164:107-122

- Harwood J, King S, Booth C, Donovan C, Schick RS, Thomas L, New L (2016) Understanding the population consequences of acoustic disturbance for marine mammals. Adv Exp Med Biol 875:417-423

Hiby L, Lovell P (1998) Using aircraft in tandem formation to estimate abundance of harbour porpoise. Biometrics 54: 1280-1289

> IJsseldijk LL, Camphuysen CJ, Nauw JJ, Aarts G (2015) Going with the flow: tidal influence on the occurrence of the harbour porpoise (Phocoena phocoena) in the Marsdiep area. Neth J Sea Res 103:129-137

Johnston DW, Westgate AJ, Read AJ (2005) Effects of finescale oceanographic features on the distribution and movements of harbour porpoises Phocoena phocoena in the Bay of Fundy. Mar Ecol Prog Ser 295:279-293

> Jones AR, Hosegood P, Wynn RB, De Boer MN, ButlerCowdry S, Embling CB (2014) Fine-scale hydrodynamics influence the spatio-temporal distribution of harbour porpoises at a coastal hotspot. Prog Oceanogr 128:30-48

Kastelein RA (1998) Food consumption and growth of marine mammals. PhD thesis, Landbouwuniversiteit Wageningen

Kastelein RA, de Haan D, Verboom WC (2007) The influence of signal parameters on the sound source localization ability of a harbor porpoise (Phocoena phocoena). J Acoust Soc Am 122:1238-1248

> Kastelein RA, Gransier R, Hoek L, Olthuis J (2012) Temporary threshold shifts and recovery in a harbor porpoise (Phocoena phocoena) after octave-band noise at $4 \mathrm{kHz}$. $\mathrm{J}$ Acoust Soc Am 132:3525-3537

Ketten DR (2004) Experimental measures of blast and acoustic trauma in marine mammals. ONR Final Rep N000149711030. Woods Hole Oceanographic Insitution, Woods Hole, MA

> King SL, Schick RS, Donovan C, Booth CG, Burgman M, Thomas L, Harwood J (2015) An interim framework for assessing the population consequences of disturbance. Methods Ecol Evol 6:1150-1158

Koschinski S (2011) Underwater noise pollution from munitions clearance and disposal, possible effects on marine vertebrates, and its mitigation. Mar Technol Soc J 45:80-88

> Lucke K, Siebert U, Lepper PA, Blanchet MAA (2009) Temporary shift in masked hearing thresholds in a harbor porpoise (Phocoena phocoena) after exposure to seismic airgun stimuli. J Acoust Soc Am 125:4060-4070

> McCarthy E, Moretti D, Thomas L, DiMarzio N and others (2011) Changes in spatial and temporal distribution and vocal behavior of Blainville's beaked whales (Mesoplodon densirostris) during multiship exercises with midfrequency sonar. Mar Mamm Sci 27:E206-E226

> Nabe-Nielsen J, Tougaard J, Teilmann J, Lucke K, Forchhammer MC (2013) How a simple adaptive foraging strategy can lead to emergent home ranges and increased food intake. Oikos 122:1307-1316

> Nabe-Nielsen J, Sibly RM, Tougaard J, Teilmann J, Sveegaard S (2014) Effects of noise and by-catch on a Danish harbour porpoise population. Ecol Model 272:242-251

New LF, Clark JS, Costa DP, Fleishman E and others (2014) Using short-term measures of behaviour to estimate long-term fitness of southern elephant seals. Mar Ecol Prog Ser 496:99-108

Nowacek DP, Thorne LH, Johnston DW, Tyack PL (2007) Responses of cetaceans to anthropogenic noise. Mammal Rev 37:81-115
NRC (National Research Council) (2005) Marine mammal populations and ocean noise: determining when noise causes biologically significant effects. The National Academies Press, Washington, DC

OSPAR Commission (2010) Quality status report. Assessment of the impact of dumped conventional and chemical munitions. OSPAR Commission, London

> Otani S, Naito Y, Kato A, Kawamura A (2001) Oxygen consumption and swim speed of the harbor porpoise Phocoena phocoena. Fish Sci 67:894-898

Read AJ, Westgate AJ (1997) Monitoring the movements of harbour porpoises (Phocoena phocoena) with satellite telemetry. Mar Biol 130:315-322

Reeder DM, Kramer KM (2005) Stress in free-ranging mammals: integrating physiology, ecology, and natural history. J Mammal 86:225-235

Richardson WJ, Greene CR, Malme CI, Thomson DH (1995) Marine mammals and Noise. Academic Press, San Diego, CA

Rue H, Martino S, Chopin N (2009) Approximate Bayesian inference for latent Gaussian models using integrated nested Laplace approximations (with discussion). J R Stat Soc B 71:319-392

Scheidat M, Gilles A, Kock KH, Siebert U (2008) Harbour porpoise Phocoena phocoena abundance in the southwestern Baltic Sea. Endang Species Res 5:215-223

> Scheidat M, Verdaat H, Aarts G (2012) Using aerial surveys to estimate density and distribution of harbour porpoises in Dutch waters. J Sea Res 69:1-7

Sertlek HÖ, Ainslie MA (2014) A depth-dependent formula for shallow water propagation. J Acoust Soc Am 136: 573-582

> Shafiei Sabet S, Neo YY, Slabbekoorn H (2015) The effect of temporal variation in sound exposure on swimming and foraging behaviour of captive zebrafish. Anim Behav 107:49-60

Southall BL, Bowles AE, Ellison WT, Finneran JJ and others (2007) Marine mammal noise exposure criteria: initial scientific recommendations. Aquat Mamm 33:411-521

Sveegaard S, Teilmann J, Tougaard J, Dietz R, Mouritsen KN, Desportes G, Siebert U (2011) High density areas for harbor porpoises (Phocoena phocoena) identified by satellite tracking. Mar Mamm Sci 27:230-246

Teilmann J, Christiansen CT, Kjellerup S, Dietz R, Nachman G (2013) Geographic, seasonal, and diurnal surface behavior of harbor porpoises. Mar Mamm Sci 29:E60-E76

Thompson PM, Brookes KL, Graham IM, Barton TR, Needham K, Bradbury G, Merchant ND (2013a) Short-term disturbance by a commercial two-dimensional seismic survey does not lead to long-term displacement of harbour porpoises. Proc R Soc Lond B Biol Sci 280:20132001

Thompson PM, Hastie GD, Nedwell J, Barham R and others (2013b) Framework for assessing impacts of pile-driving noise from offshore wind farm construction on a harbour seal population. Environ Impact Assess Rev 43:73-85

> Tougaard J, Wright AJ, Madsen PT (2015) Cetacean noise criteria revisited in the light of proposed exposure limits for harbour porpoises. Mar Pollut Bull 90:196-208

van Horne B (1983) Density as a misleading indicator of habitat quality. J Wildl Manag 47:893-901

> Von Benda-Beckmann AM, Aarts GM, Sertlek OS, Lucke K and others (2015) Assessing the impact of underwater clearance of historical explosives on harbour porpoises (Phocoena Phocoena) in the southern North Sea. Aquat Mamm 41:503-523 